\title{
HUBUNGAN KINERJA PENYULUH PERTANIAN LAPANGAN DENGAN KEBERHASILAN PETERNAK SAPI POTONG DI KECAMATAN KWANDANG KABUPATEN GORONTALO UTARA
}

\author{
Ismail Dali, Fietje S. Oley, Anneke K. Rintjap*, Judy M. Tumewu \\ Fakultas Peternakan Universitas Sam Ratulangi Manado, 95115
}

\begin{abstract}
ABSTRAK
Berdasarkan nilai rasio jumlah desa terhadap jumlah PPL, yang berarti bahwa satu PPL dapat melaksanakan tugasnya pada satu desa, maka sistem penyuluhan di kecamatan Kwandang seharusnya sudah berjalan baik. Namun demikian, berdasarkan survey pendahuluan oleh peneliti bahwa kinerja penyuluh dibeberapa desa di kecamatan Kwandang nampak memperlihatkan kinerja yang kurang maksimal. Sementara itu bahwa tinggi rendahnya kinerja PPL berdampak pada keberhasilan peternak. Jika kinerja penyuluh kurang baik, maka penyuluh harus memperbaiki kinerjanya, sebaliknya jika kinerja penyuluh baik, berarti penyuluh tersebut sudah menjalankan fungsinya dengan baik. Penelitian ini bertujuan untuk mengetahui kinerja penyuluh pertanian lapangan (PPL), keberhasilan peternak sapi potong, serta menganalisis hubungan antara kinerja penyuluh pertanian lapangan dengan keberhasilan peternak sapi potong di kecamatan Kwandang kabupaten Gorontalo Utara. Penentuan sampel desa ditentukan secara sengaja (Puposive) yaitu desa Ombulodata, Alata Karya, dan Posso. Pemilihan responden peternak menerapkan metode stratified random sampling berdasarkan banyaknya jumlah peternak sebagai populasi dari seluruh peternak yang ada di desa sampel terpilih dengan menggunakan rumus Slovin, sedangkan responden penyuluh pertanian lapangan ditentukan secara sengaja dengan memilih PPL yang bertugas pada sampel desa
\end{abstract}

*Korespondensi (corresponding author): Email : anneke_rintjap@yahoo.com terpilih. Pengukuran parameter penelitian dilakukan dengan menerapkan skala Likert.Pengujian hubungan antara variabel kinerja PPL dengan keberhasilan peternak sapi potongmenggunakan uji koefisien korelasi Spearman.Hasil penelitian menunjukkan bahwa kinerja PPL sebagian besar berada dalam kategori baik dengan persentase $96,67 \%$, keberhasilan peternak sapi potong sebagian besar berada dalam kategori baik dengan persentase $57,58 \% \%$, dan terdapat hubungan yang kuat antara kinerja PPL dengan keberhasilan peternak sapi potong dengan nilai korelasi rs = 0,6942 dan z-hitung $(3,9269)>$ z-tabel $(1,960)$. Berdasarkan hasil penelitian dapat disimpulkan bahwa kinerja PPL sebagian besar dalam kategori baik, keberhasilan PPL sebagian besar dalam kategori baik, dan terdapat hubungan yang kuat antara kinerja PPL dengan keberhasilan peternak sapi potong di kecamatan Kwandang Kabupaten Gorontalo Utara

Kata Kunci : Kinerja PPL, Keberhasilan Peternak Sapi Potong

\section{ABSTRACT}

RELATIONSHIP

BETWEEN

AGRICULTURAL EXTENTION TASK EFFORTS AND BEEF CATTLE HOUSEHOLD FARMER SUCCCESS AT KWANDANG DISTRICT OF NORTH GORONTALO REGENCY. On basis of the ratio between total of villages and total of agricultural extension officers (AEO), meaning each AEO worked one village, the system of the AEO should run smoothly. Based on the initial survey, it showed that task effort of the 
AEO at several villages of Kwandang district, indicated minimum task effort by the AEO. Low task effort affected productivity success of beef cattle household farmers indicating it should be improved. The objective of this study was to evaluate the task effort of the AEO, the success of beef cattle household farmers, and to analyze the relationship between the AEO and beef cattle household success at Kwandang district of North Gorontalo regency. The purposive sampling method was applied in this study involving four villages of Ombulodata, Alata Karya, and Posso. The household respondents were choosed based on stratified random sampling of the total population of all household farmers at each village using Slovin formula, completed by the AEO working at the sample villages. Variable measurements were applied using Liker scale.The relationship between the AEO and beef cattle household success was tested using Spearman correlation coefficient test. Results showed that task effort of the AEO was included into good category with the percentage of 96.67 percents. The household success was also included into good category with the percentages of 57.58 percents. In addition, there was strong relationship between task effort and beef cattle household success with the correlation value of 0.6942 indicated by $\mathrm{z}$-calculated of $3.9269>\mathrm{z}$ table of 1.960. Therefore, it can be concluded that the task effort of the AEO and beef cattle household farmer success were categorized into good condition indicated by strong relationship between those two variables at Kwandang district of North Gorontalo regency.

Keywords : AEO Performance, Succes of Beef Cattle Ranchers

\section{PENDAHULUAN}

\section{Latar Belakang}

Langkah efektif yang dapat ditempuh dalam rangka mempercepat laju proses pembangunan peternakan adalah dengan melakukan pengembangan peternak melalui program pembangunan peternakan. Program pembangunan peternakan yang dimaksud merupakan rangkaian upaya perwujudan pembangunan peternakan yang mampu meningkatkan kesejahteraan peternak, agar dapat berjalan lancar membutuhkan adanya kegiatan penyuluhan atau pendidikan tentang pembangunan.

Hal tersebut diatas berarti bahwa dalam upaya pemberdayaan peternak sangat membutuhkan penyuluh yang memiliki kinerja sangat baik sehingga proses pemberdayaan peternak dapat sesuai dengan tujuan pemberdayaan yang disebutkan dalam UU SP3K Nomor 16 tahun 2006 tentang penyuluhan pertanian, perikanan, dan kehutanan Dengan kata lain, tinggi rendahnya tingkat perkembangan peternak sangat dipengaruhi oleh besarnya peran penyuluh.

Berdasarkan data Balai Penyuluhan Pertanian, Perikanan, dan Kehutanan (BP3K) Kecamatan Kwandang tahun 2016, penyuluh pertanian lapangan (PPL) yang tersebar di 18 desa Kecamatan Kwandang berjumlah 14 orang, terdiri dari 
empat orang PNS dan 10 orang PTT. PPL khusus bidang peternakan berjumlah satu orang dan PPL polivalen atau PPL campuran baik bidang peternakan, pertanian, dan perikanan berjumlah 13 orang. Menurut beberapa informasi bahwa kegiatan penyuluhan disetiap desa diprioritaskan ke pangan atau bidang pertanian tetapi kegiatan penyuluhan untuk bidang peternakan tetap dijalankan.

Melihat hal tersebut diatas bahwa dengan nilai rasio jumlah desa terhadap jumlah PPL, yang berarrti bahwa satu PPL dapat melaksanakan tugasnya pada satu desa, maka sistem penyuluhan di kecamatan Kwandang seharusnya sudah berjalan baik. Namun demikian, berdasarkan survey pendahuluan oleh peneliti bahwa kinerja penyuluh dibeberapa desa di kecamatan Kwandang nampak memperlihatkan kinerja yang kurang maksimal. Sementara itu bahwa tinggi rendahnya kinerja PPL berdampak pada keberhasilan peternak. Jika kinerja penyuluh kurang baik, maka penyuluh harus memperbaiki kinerjanya, sebaliknya jika kinerja penyuluh baik, berarti penyuluh tersebut sudah menjalankan fungsinya dengan baik.

Berdasarkan hal-hal yang telah dikemukakan maka dilakukan penelitian yang bertujuan untuk mengkaji kinerja PPL dan keberhasilan peternak sapi potong di Kecamatan Kwandang Kabupaten
Gorontalo Utara, serta menganalisis hubungan antara kedua variabel tersebut dengan melakukan penelitian yang berjudul "Hubungan Kinerja Penyuluh Pertanian Lapangan dengan Keberhasilan Peternak Sapi Potong di Kecamatan Kwandang Kabupaten Gorontalo Utara”

\section{METODE PENELITIAN}

\section{Waktu dan tempat}

Penelitian ini dilaksanakan pada tanggal 20 Desember 2016 sampai dengan 19 Januari 2017 di kecamatan Kwandang kabupaten Gorontalo Utara.

\section{Sampel penelitian}

Penilaian sampel desa ditentukan secara sengaja (Puposive).Dasar pertimbangan yang dipakai dalam memilih sampel desa adalah desa yang terdapat kelompok tani ternak yang masih aktif dandesa yang masih mendapatkan penyuluhan dari PPLyaitu desa Ombulodata, Alata Karya, dan Posso. Dalam tiga desa ini terdapat kelompok tani ternak yaitu Poktan Ombulodata Karya, Karya Nyata 1, Mekar Jaya, Galamis, Karya Nyata, Huyula, Bali Perkasa, Karya Bersama, dan poktan Tani Makmur.

Pemilihan responden peternak menggunakan rumus Slovin dengan toleransi kesalahan sebesar $15 \%$. Menurut Sevilla et al (2006), rumus slovin merupakan salah satu metode yang 
digunakan untuk menentukan jumlah sampel. Rumus tersebut sebagai berikut :

$$
\mathrm{n}=\frac{N}{N(e)+1}
$$

Keterangan :

$$
\begin{aligned}
& \mathrm{n} \quad=\text { jumlah sampel peternak } \\
& \mathrm{N} \quad \begin{array}{l}
\text { jumlah populasi peternak } \\
\text { pada desa sampel }
\end{array} \\
& \mathrm{e} \quad=\text { batas toleransi error } 15 \% \\
& \mathrm{n}=\frac{130}{130\left(15^{2}\right)+1} \\
& \mathrm{n}=\frac{130}{130\left(0.15^{2}\right)+1} \\
& \mathrm{n}=\frac{130}{130(0.0225)+1}=33,12 \approx 33
\end{aligned}
$$

Jadi total responden untuk peternak didapat sebanyak 33 orang dalam tiga desa. Sampel penyuluh pertanian lapangan (PPL) ditentukan berdasarkan total sampling dengan memilih PPL yang bertugas pada sampel desa terpilihyaitu berjumlah tiga orang

\section{Metode pengumpulan data}

Penelitian ini menggunakan data primer dan data sekunder. Data primer diperoleh denganmetode wawancara langsung ke peternak dan PPL dengan menggunakan daftar pertanyaan yang telah disediakan sebelumnya mengenai kinerja PPL dan keberhasilan peternak sapi potong.

Data sekunderdiperoleh dari Dinas Peternakan Kabupaten Gorontalo Utara yaitu form populasi ternak pada sampel kelompok tani ternak di desa sampel, data dari BP3K Kecamatan Kwandang yaitu mengenai programa penyuluhan, serta data dari BPS Kabupaten Gorontalo Utara
(Serial Online) yaitu gambaran umum lokasi penelitian.

\section{Definisi variabel dan pengukuran}

Variabel yang diukur dalam penelitian ini adalah kinerja PPL dan keberhasilan peternak. Kinerja PPL merupakan suatu ukuran tingkat pencapaian hasil pelaksanaan kegiatan dari seorang penyuluh serta bagaimana karakteristik dari penyuluh tersebut dalam proses pelaksanaan kegiatannya. Sedangkan keberhasilan peternak merupakan suatu keadaan yang menggambarkan keadaan lebih baik daripada sebelumnya. Dalam hal ini adalah perubahan perilaku peternak (pengetahuan, sikap, dan keterampilan) dan perkembangan usaha ternak sapi potong.Variabel yang diukur dijabarkan menjadi sub variabel, kemudian dijabarkan menjadi indikator variabel, dan dijabarkan menjadi parameter. Parameter tersebut dijadikan sebagai titik tolak untuk menyusun item-item instrumen yang dapat berupa pernyataan atau pertanyaan.

Alat analisis yang digunakan dalam pengukuran parameter penelitian dilakukan dengan menerapkan skala Likert. Skala Likert dengan pengukurannya diberi skor untuk setiap parameter. Dalam membantu analisis data digunakan skor untuk pertanyaan dengan respon yang termasuk dalam kategori 
sangat baik/sangat berhasil diberikan skor 5, sebaliknya jika respon termasuk dalam kategori tidak baik/tidak berhasil diberikan skor 1.

\section{Analisis Data}

Penentuan skor dihitung berdasarkan hasil skor kinerja PPL dan keberhasilan peternak yang di dapat dengan cara menjumlahkan skor sesuai dengan jumlah pertanyan yang ada pada setiap variabel, sub variabel, dan indikator penilaian. Penentuan kategori kinerja PPL dan keberhasilan peternak sapi potong di kecamatan Kwandang kabupaten Gorontalo utara ditentukan dengan menggunakan asumsi dasar Interval kelasyang dikemukakan oleh Dajan (2004). Adapun rumus yang digunakan adalah sebagai berikut :

Keterangan:

$$
\mathrm{I}=\frac{\text { Skor tertinggi }- \text { Skor terendah }}{\text { Banyaknya kategori }}
$$

$\mathrm{I}=$ Interval kelas

SMa $=$ STi $x$ Jumlah Pertanyaan

SMi $=$ STa $\mathrm{x}$ Jumlah pertanyaan

$\mathrm{BK}=$ Jumlah kategori (5)

Menguji hubungan variabel kinerja

PPL dengan keberhasilan peternak sapi potong digunakan uji koefisien korelasi Spearman. Riduwan (2010).Model korelasi jenjang Spearman yang digunakan adalah :

$$
r_{s}=1-\frac{6 \sum d^{2}}{n\left(n^{2}-1\right)}
$$

Keterangan :

$r_{s}=$ Nilai korelasi jenjang spearman

$\sum d^{2}=$ total kuadrat selisih antar ranking

$\mathrm{n} \quad=$ jumlah sampel penelitian

Setelah mendapatkan nilai koefisien korelasi, maka selanjutnya digunakan uji Z karena sampel > 30 atau $n$ $=$ 33. Pengambilan keputusan adalah dengan membandingkan nilai z-hitung dengan nilai $z$-tabel $(\boldsymbol{\alpha}=5 \%)$. Adapun rumus z-hitung yang digunakan adalah sebagai berikut.

$$
\text { Z-hitung }=r_{s} \sqrt{n-1}
$$

\section{Keterangan :}

$$
\begin{array}{ll}
\mathrm{z} & =\text { nilai } \mathrm{z} \text {-hitung } \\
r_{\mathrm{S}} & =\text { Nilai korelasi spearman } \\
\mathrm{n} & =\text { total jumlah sampel penelitian }
\end{array}
$$

\section{HASIL DAN PEMBAHASAN}

\section{Penilaian kinerja penyuluh pertanian lapangan (PPL)}

Penyuluh pertanian lapangan yang dijadikan responden berjumlah tiga orang yang merupakan sampel dari populasi yang tersebar di 18 desa dan juga bertugas pada sampel desa terpilih yaitu desa Ombulodata, Alata Karya dan Posso. Hasil penilaian PPL berdasarkan variabel yang diukur yaitu kinerja disajikan dalam tabel 1 berikut. 
Tabel 1. Distribusi penilaian PPL berdasarkan kinerja

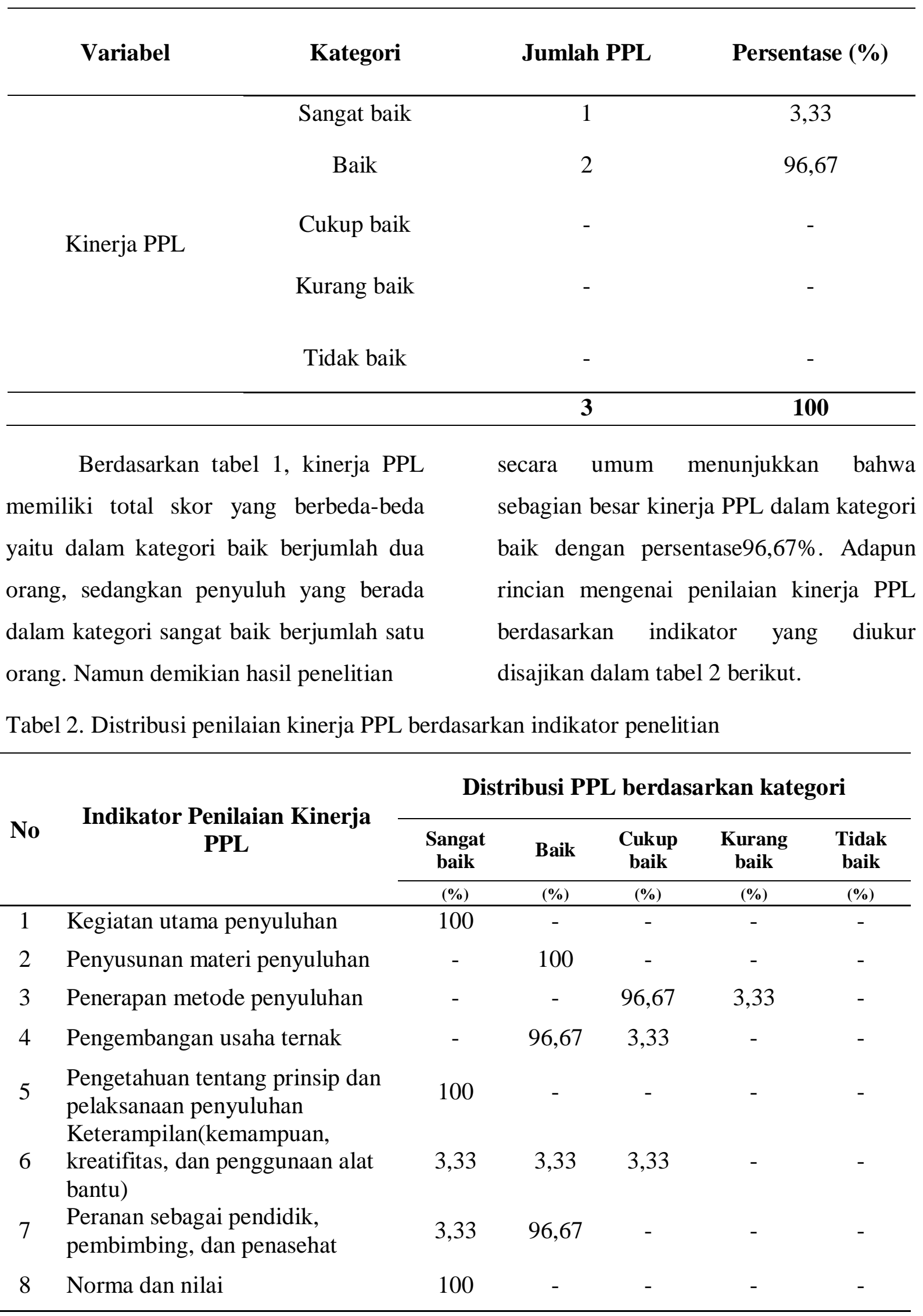


Tabel 2 menunjukkan bahwa indikator kinerja PPL ditinjau dari beberapa aspek, kinerja PPL yang sangat baik yaitu kegiatan utama penyuluhan, pengetahuan tentang prinsip dan pelaksanaan penyuluhan, norma dan nilai PPL dengan persentase penyuluh sebesar 100\%. Hal ini menunjukkan bahwa kinerja PPL sudah sangat baik dalam melaksanakan kegiatan pelatihan, melakukan kegiatan kunjungan, memberikan materi penyuluhan sesuai dengan kebutuhan peternak, kelengkapan bahan ajar penyuluhan, meningkatkan hasil ternak kelompok tani, norma PPL yang menjadikan peternak sebagai sahabat dan bukan merasa sebagai pemimpin, serta tanggung jawab PPL atas pekerjaannya.

Hasil penilaian kinerja PPL di lokasi penelitian menggambarkan bahwa PPL telah melaksanakan tugas pokok dan fungsinya dengan baik, dimana hal ini juga didukung oleh karakteristik inividu penyuluh seperti pengetahuan, keterampilan, peranan, dan nilai PPL yang baik dalam proses pelaksanaan teknis dilapangan. Hal ini sejalan dengan hasil penelitian Sapar et al (2012) bahwa karakteristik berpengaruh nyata pada kompetensi penyuluh pertanian. Hal ini berarti karakteristik penyuluh pertanian ikut menentukan baik buruknya kompetensi mereka. Pengaruh karakteristik pada kompetensi penyuluh pertanian nampak pada baik-buruknya kinerja penyuluh melakukan perencanaan penyuluhan, evaluasi dan pelaporan penyuluhan, pengembangan penyuluhan pertanian dan diseminasi teknologi.

Yanto (2016) mengemukakan bahwa salah satu faktor yang berkaitan dengan komunikasi kebijakan penyuluhan pertanian pada penyuluh pertanian lapangan (PPL) adalah konsistensi. Jika implementasi kebijakan penyuluhan pertanian ingin berlangsung secara efektif, maka perintah-perintah pelaksanaan harus konsisten. Walaupun perintah-perintah yang disampaikan kepada para PPL mempunyai unsur yang jelas, tetapi jika perintah itu bertentangan maka perintah itu tidak akan memudahkan para palaksana kebijakan menjalankan tugasnya dengan baik.

\section{Penilaian keberhasilan peternak sapi potong}

Dalam penelitian ini, peternak sapi potong yang dijadikan responden sebanyak 33 orang yang terdapat dalam tiga sampel desa dan diambil secara proporsional untuk mendapatkan data yang akurat dan terwakili berdasarkan kecamatan. Rincian data mengenai keberhasilan peternak sapi potong di kecamatan Kwandang kabupaten Gorontalo Utara disajikan dalam tabel 3. 
Tabel 3. Distribusi peternak sapi potong berdasarkan variabel keberhasilan

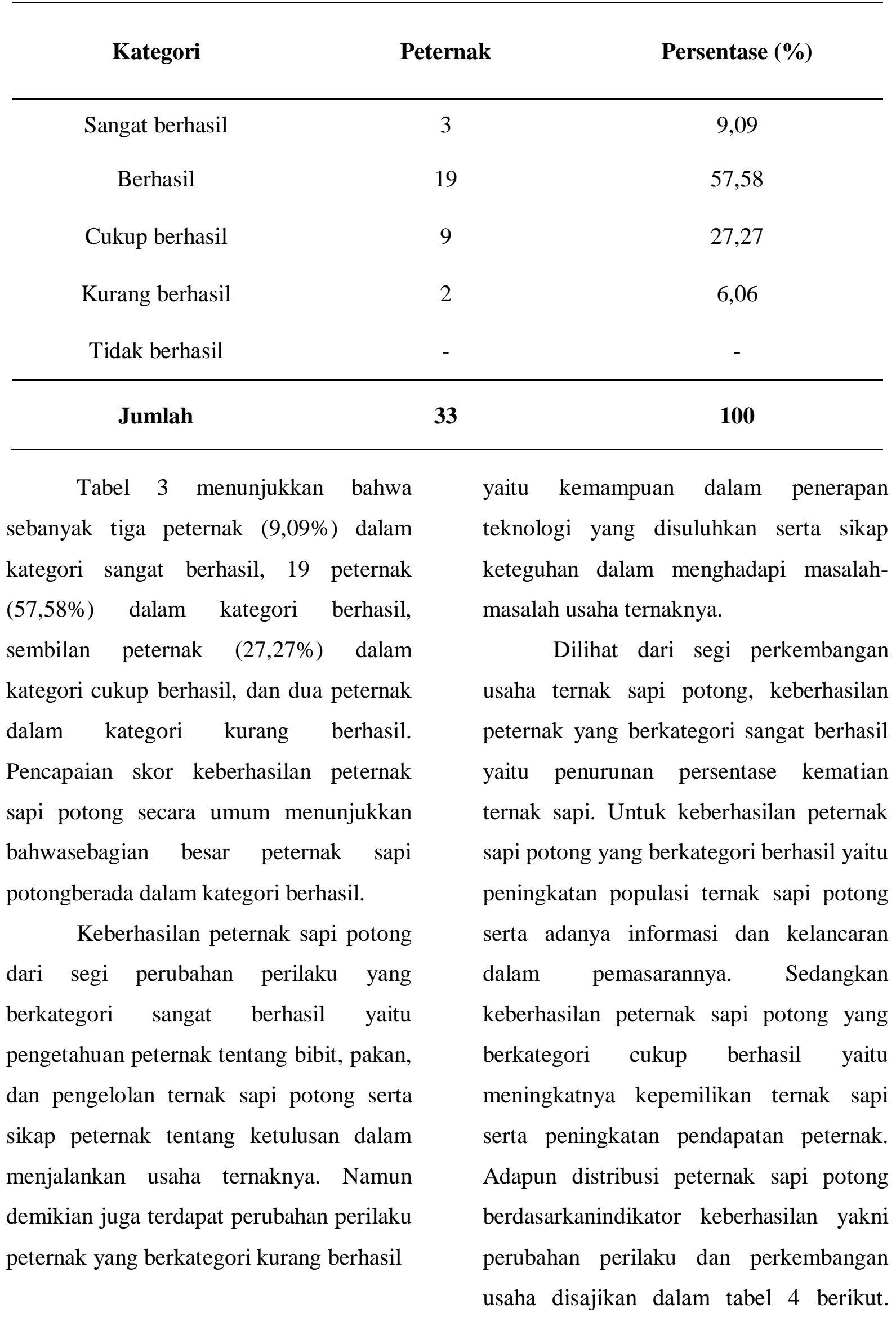


Tabel 4. Distribusi peternak sapi potong berdasarkan indikator keberhasilan

\begin{tabular}{llccccc}
\hline & \multirow{6}{*}{ Kategori Nilai } \\
\cline { 3 - 7 } No & $\begin{array}{c}\text { Indikator Penilaian } \\
\text { Keberhasilan peternak }\end{array}$ & $\begin{array}{c}\text { Sangat } \\
\text { berhasil }\end{array}$ & Berhasil & $\begin{array}{c}\text { Cukup } \\
\text { berhasil }\end{array}$ & $\begin{array}{c}\text { Kurang } \\
\text { berhasil }\end{array}$ & $\begin{array}{c}\text { Tidak } \\
\text { berhasil }\end{array}$ \\
\cline { 3 - 7 } & $(\boldsymbol{\%})$ & $(\boldsymbol{\%})$ & $(\boldsymbol{\%})$ & $(\boldsymbol{\%})$ & $(\boldsymbol{\%})$ \\
\hline 1 & Perubahan perilaku & 3,04 & 48,48 & 48,48 & - & - \\
2 & Perkembangan usaha & 39,39 & 30,30 & 24,24 & 6,07 & - \\
\hline
\end{tabular}

Tabel 4 menunjukkan bahwa dari aspek perubahan perilaku, satu peternak $(3,04 \%)$ berada pada kategori sangat berhasil, 16 peternak $(48,48 \%)$ berada pada kategori berhasil, dan 16 peternak $(48,48 \%)$ lainnya berada pada kategori cukup berhasil. Ditinjau dari aspek perkembangan usaha, distribusi peternak sapi potong yang berada dalam kategori sangat berhasil sebanyak 13 orang $(39,39 \%)$, kategori berhasil sebanyak 10 orang (30,30\%), kategori cukup berhasil sebanyak delapan orang $(24,24 \%)$, dan kategori kurang berhasil sebanyak dua orang $(6,07 \%)$. Rincian data mengenai keberhasilan peternak berdasarkan parameter yang diukur disajikan dalam tabel 5 berikut.

Tabel 5. Distribusi peternak sapi potong berdasarkan parameter keberhasilan

\begin{tabular}{|c|c|c|c|c|c|}
\hline \multirow{3}{*}{$\begin{array}{l}\text { Parameter keberhasikan } \\
\text { peternak sapi potong }\end{array}$} & \multicolumn{5}{|c|}{ Kategori Nilai } \\
\hline & $\begin{array}{c}\text { Sangat } \\
\text { berhasil }\end{array}$ & Berhasil & $\begin{array}{c}\text { Cukup } \\
\text { berhasil }\end{array}$ & $\begin{array}{l}\text { Kurang } \\
\text { berhasil }\end{array}$ & $\begin{array}{c}\text { Tidak } \\
\text { berhasil }\end{array}$ \\
\hline & (\%) & $(\%)$ & $(\%)$ & $(\%)$ & $(\%)$ \\
\hline $\begin{array}{l}\text { Meningkatnya pengetahuan } \\
\text { peternak tentang bibit, } \\
\text { pakan, dan pengelolaan } \\
\text { ternak sapi potong }\end{array}$ & 72,73 & 12,12 & - & 15,15 & - \\
\hline $\begin{array}{l}\text { Kemampuan } \\
\text { penerapan teknologi yang } \\
\text { disuluhkan }\end{array}$ & - & 3,03 & 42,42 & 24,24 & 30,31 \\
\hline $\begin{array}{l}\text { Ketulusan dalam usaha } \\
\text { ternaknya }\end{array}$ & 60,61 & 24,24 & 15,15 & - & - \\
\hline $\begin{array}{l}\text { Keteguhan dalam } \\
\text { menghadapi masalah usaha } \\
\text { ternaknya }\end{array}$ & 3,03 & 15,15 & - & 81,82 & - \\
\hline $\begin{array}{l}\text { Meningkatnya } \quad \text { populasi } \\
\text { ternak sapi }\end{array}$ & 36,36 & 27,27 & 15,15 & 9,10 & 12,12 \\
\hline $\begin{array}{l}\text { Meningkatnya kepemilikan } \\
\text { ternak sapi }\end{array}$ & 24,24 & 21,21 & 21,21 & 15,16 & 18,18 \\
\hline $\begin{array}{l}\text { Penurunan persentase } \\
\text { kematian ternak sapi potong }\end{array}$ & 96,97 & 3,03 & - & - & - \\
\hline $\begin{array}{l}\text { Adanya informasi dan } \\
\text { kelancaran pemasaran }\end{array}$ & 12,12 & 60,61 & 27,27 & - & - \\
\hline $\begin{array}{l}\text { Peningkatan pendapatan } \\
\text { peternak sapi potong }\end{array}$ & 6,06 & 33,33 & 36,36 & 18,19 & 6,06 \\
\hline
\end{tabular}


Berdasarkan tabel 5 bahwa keberhasilan peternak sapi potong masih terdapat beberapa peternak yang berada dalam kategori kurang berhasil bahkan ada yang berada dalam kategori tidak berhasil. Secaraumum penilaian keberhasilan peternak sapi potong berdasarkan parameter yang diukur menunjukkan nilai yang bervariasi, sebagian besar peternak $(96,67 \%)$ berkategori sangat berhasil yakni dalam hal rendahnya persentase kematian ternak. Sedangkan aspek yang kurang berhasil dengan persentase tertinggi $(81,82 \%)$ yakni kurang berhasilnya perubahan sikap keteguhan peternak dalam menghadapi masalah-masalah dalam usaha yang dijalaninya.

Upaya peningkatan keberhasilan peternak sapi potong dapat dilakukan dengan menciptakan sebuah strategi besar yang mampu mendongkrak keberhasilan peternak sapi potong maupun pemerintah dalam proses pembangunan peternakan.

Sehubungan dengan hal tersebut di atas, Mulatmi et al (2016) menyatakan beberapa strategi dalam peningkatan adopsi inovasi yaitu mengoptimalkan sumber daya baik modal manusia yang Tabel 6. Hasil analisis hubungan kinerja PPL dengan keberhasilan peternak sapi potong

\begin{tabular}{cccc}
\hline Variabel & \multicolumn{3}{c}{ Responden $(\mathbf{n = 3 3})$} \\
\hline $\begin{array}{c}\text { Kinerja PPL }(\mathrm{x}) \\
\text { Keberhasilan peternak }(\mathrm{y})\end{array}$ & rs & z-hitung & z-tabel $\boldsymbol{\alpha}=\mathbf{0 , 0 5 / 2}$ \\
\hline
\end{tabular}

berasal dari diri peternak maupun eksternal seperti ternak yang dimiliki, lingkungan, serta pemerintah; memberikan informasi yang jelas dan kontinyu mengenai inovasi; mempermudah akses informasi dengan memperbanyak penyebaran informasi; memberikan program pendampingan, penyuluhan, dan pelatihan disertai demonstrasi mengenai inovasi; meningkatkan partisipasi peternak; memperkuat kelembagaan peternak; mengusahakan alat pendukung inovasi secara bersama-sama; meningkatkan kualitas penyuluh, media, dan cara penyampaian informasi; serta mengoptimalkan bantuan pemerintah dan LSM.

\section{Analisis hubungan kinerja penyuluh pertanian lapangan (PPL) dengan keberhasilan peternak sapi potong di lokasi penelitian}

Analisis data mengenai hubungan kinerja PPL dengan keberhasilan peternak sapi potong digunakan uji korelasi spearman (rs).Selanjutnya digunakan uji Z karena sampel > 30 atau $n=33$. Hasil analisis data disajikan dalam tabel 6 berikut. 
Berdasarkan nilai z-tabel dengan tingkat kepercayaan sebesar95\% maka hasil analisis data menggunakan uji dua sisi (two-tailed) menunjukkan bahwa nilai z-hitung > nilai z-tabel, maka ho : kinerja PPL tidak berhubungan dengan keberhasilan peternak sapi potong ditolak dan ha : kinerja PPL berhubungan dengan keberhasilan peternak sapi potong diterima. Dapat disimpulkan bahwa dengan melihat nilai korelasi Spearman Rho dan perbandingan nilai z-hitung dengan z-tabel, maka terdapat hubungan yang kuat antara kinerja PPL (x) dengan keberhasilan peternak sapi potong (y).

Far (2014) menyatakan bahwa sebagai sistem pendidikan non formal, penyuluhan pertanian merupakan suatu usaha untuk menimbulkan perubahan perilaku peternak seperti perubahan pengetahuan yang lebih luas, perubahan keterampilan teknis yang lebih baik serta perubahan sifat untuk lebih produktif sehingga para peternak dapat memperbaiki cara berusaha ternak agar lebih menguntungkan.

Hakim dan Sugihen (2007) mengemukakan bahwa besaran pengaruh lingkungan sosial khususnya norma dan nilai budaya lokal menunjukkan bahwa keberhasilan mengelola program, tujuan kelompok, dan peningkatan produktivitas kerja petani adalah dengan tanpa mengabaikan tradisi, nilai-nilai sosial budaya, adat kebiasaan, kepercayaan dan kebutuhan-kebutuhan yang dirasakan dalam lingkungan sosial sekitarnya.

Makatitaet al (2014) menyimpulkan bahwa tingkat efektivitas metode penyuluhan yang ditunjukkan oleh kemampuan penyuluh, keadaan alat bantu penyuluhan, kesesuaian dengan waktu dan tempat penyuluhan, materi penyuluhan, kesesuaian dengan kondisi dan tingkat adopsi sasaran, kesesuaian dengan tujuan yang ingin dicapai, menunjukkan ciri-ciri yang baik. Selanjutnya dinyatakan bahwa penyuluhan yang dilakukan, dengan metode pendekatan kelompok menunjukkan hasil yang cukup baik terhadap peningkatan kemampuan beternak oleh peternak, juga terhadap pengembangan peternakan sapi potong.

Secara holistik Amanah (2007) mengemukakan bahwa penyuluhan sangat diperlukan eksistensinya untuk mendukung kehidupan umat manusia. Revitalisasi lembaga penyuluhan diperlukan agar layanan penyuluhan dapat mencapai seluruh wilayah di Indonesia. Komitmen pemerintah untuk merevitalisasi penyuluhan beserta sarana dan prasarana pendukungnya mutlak diperlukan. Sinergisme pemerintah, masyarakat, peneliti dan penyuluh merupakan kunci keberhasilan penyuluhan. Dengan demikian dapat disimpulkan bahwa kesuksesan pemerintah 
dalam program penyuluhan dilihat dari baik buruknya kinerja penyuluh pertanian lapangan (PPL) dan kesuksesan seorang PPL dilihat dari suksesnya peternak yang yang menjadi binaannya.

\section{KESIMPULAN}

Berdasarkan hasil penelitian, dapat disimpulkan bahwa kinerja penyuluh pertanian lapangan (PPL) dan keberhasilan peternak sapi potong sebagian besar berada dalam kategori baik, sertaterdapat hubungan yang kuat antara kinerja PPL dengan keberhasilan peternak sapi potong di kecamatan Kwandang Kabupaten Gorontalo Utara.

\section{DAFTAR PUSTAKA}

Amanah, S. 2007. Makna Penyuluhan dan Transformasi Perilaku Manusia. Jurnal Penyuluhan. 3 (1) : 63-67.

BP3K Kecamatan Kwandang. 2016. Programa Kecamatan Kwandang. BP3K

Dajan, A. 2004. Pengantar Metode Statistik Jilid II. Jakarta: LP3ES.

Far, R. A. F. 2014. Respon Petani Terhadap Penerapan Metode Penyuluhan Pertanian di Kota Ambon Provinsi Maluku. Jurnal Budidaya Pertanian. 10 (1) :48-51.

Hakim, L. dan B. G. Sugihen. 2007. Pemberdayaan Petani Sayuran:Kasus Petani Sayuran di Sulawesi Selatan. Disertasi. Sekolah Pascasarjana. Institut Pertanian Bogor. Bogor. Hal : 1-205.
Makatita, J., Isbandi, dan S. Dwidjatmiko. 2014. Tingkat Efektifitas Penggunaan Metode Penyuluhan Pengembangan Ternak Sapi Potong di Kabupaten Buru Provinsi Maluku. Jurnal Agromedia. 32 (2) : 64-74.

Mulatmi, S. N. W., B. Guntoro, B. P. Widyobroto, S. Nurtini, dan A. Pertiwiningrum. 2016. Strategi Peningkatan Adopsi Inovasi pada Peternakan Sapi Perah Rakyat di Daerah Istimewa Yogyakarta, Jawa Tengah, dan Jawa Timur. Buletin Peternakan. 40 (3) :219-227.

Riduwan. 2010. Metode dan Teknik Menyusun Tesis. Bandung: PT Alfabeta.

Sapar, A. Jahi, P. S. Asngari, Amiruddin, dan I. G. P. Purnaba. 2012.Kinerja Penyuluh Pertaniandan Dampaknya pada Kompetensi Petani Kakaodi Empat Wilayah Sulawesi Selatan. Jurnal Penyuluhan. 8 (1) : 29-41.

Sevilla, C. G., J. A. Ochave, T. G. Punsalan, B. P. Regala, dan G. B. Uriarte. 2006. Pengantar Metode Penelitian. UI Press. Jakarta.

Undang-Undang R.I Nomor 16 Tahun 2006 tentang SP3K. (Serial Online) $10 \quad$ September 2016. http://luk.staff.ugm.ac.id/atur/horti/U U16-2006Sistem Penyuluhan.pdf

Yanto. 2016. Implementasi Kebijakan Penyuluhan pada Penyuluh Pertanian Lapangan (PPL) di Badan Pelaksanaan Penyuluhan Pertanian, Perikanan, dan Kehutanan (BP4K) Kabupaten Karawang. Jurnal Implementasi Kebijakan Penyuluhan Pertanian.: 1-16. 